\title{
CIRUGÍA DE GRAN MASA RESIDUAL TRAS QUIMIOTERAPIA EN TUMOR GERMINAL TESTICULAR AVANZADO
}

\author{
J.M. GIMÉNEZ BACHS, A.S. SALINAS SÁNCHEZ, R. RUÍZ MONDÉJAR, \\ J.G. LORENZO ROMERO, Ma..J. DONATE MORENO, M. SEGURA MARTÍN, \\ I.R. HERNÁNDEZ MILLÁN, L. CAÑAMARES PABOLAZA, J.A. VIRSEDA RODRÍGUEZ
}

Servicio de Urología. Complejo Hospitalario Universitario de Albacete. Albacete.

Actas Urol Esp. 28 (3): 230-233, 2004

\section{RESUMEN}

CIRUGÍA DE GRAN MASA RESIDUAL TRAS QUIMIOTERAPIA EN TUMOR GERMINAL TESTICULAR AVANZADO

El tratamiento de los tumores testiculares ha avanzado de tal manera en los últimos años que se consiguen altos porcentajes de curación. Tras la quimioterapia, en muchos casos aparecen masas residuales que son susceptibles de cirugía como opción terapéutica que obtiene buenos resultados, pero que precisa un grado de entrenamiento quirúrgico avanzado ya que es una técnica dificultosa y con importantes complicaciones.

Presentamos el caso de un paciente que tras orquiectomía y quimioterapia por tumor germinal testicular avanzado, presentó masa residual de gran tamaño que precisó cirugía de la misma, consiguiéndose la extirpación radical.

PALABRAS CLAVE: Masa residual. Linfadenectomía retroperitoneal. Tumor germinal de testículo. Quimioterapia.

\section{ABSTRACT}

SURGERY OF A LARGE RETROPERITONEAL RESIDUAL MASS AFTER CHEMOTHERAPY IN ADVANCED TESTICULAR GERM CELL TUMOUR

Treatment for testicular tumours has progress in such a manner in the last years that high cure percentages can at present be achieved. After chemotherapy, in most cases, residual mass can appear. In this cases surgery is considered a viable therapeutic option although it implies an advanced surgical training since it is a complex technique and implies serious implications.

We submit the case of a patient who presented a large residual mass from a testicular germ cell tumour after being treated with orquiectomía and chemotherapy. Surgery was performed resulting in total and radical extirpation of residual mass.

KEY WORDS: Residual mass. Retroperitoneal lymph node dissection. Testicular germ cell tumour. Chemotherapy. 
$\mathrm{C}$ on el advenimiento de la quimioterapia, el tratamiento de los tumores testiculares ha variado considerablemente en los últimos años, y actualmente se consiguen altos porcentajes de curación de esta patología, que por otra parte ha sufrido un aumento de su incidencia, situándose cerca del $3 \%{ }^{1}$.

En ocasiones el diagnóstico se hace de manera tardía, bien por confusión con otras patologías que producen aumento del contenido escrotal, o bien por pudor de los pacientes que son reacios a acudir al médico por su sintomatología, teniendo en cuenta que se trata de tumores que acontecen preferentemente en individuos de corta edad.

Cuando la enfermedad es diseminada, el tratamiento de los tumores testiculares se vuelve mucho más complejo por la agresividad del tratamiento quimioterápico y por la aparición de masa residual retroperitoneal que obliga a ser mucho más cautos en la elección del tratamiento y porque la cirugía de masa retroperitoneal constituye un procedimiento complejo, no exento de complicaciones.

En el presente trabajo aportamos el caso de un paciente con enfermedad diseminada que tras quimioterapia presentó una gran masa residual que obligó a una linfadenectomía retroperitoneal y exéresis de la masa.

\section{CASO CLÍNICO}

Paciente de 20 años de edad que acude a Urgencias por tumoración testicular derecha de grandes dimensiones y de varios meses de evolución. El paciente refiere dolor de espalda y ninguna otra sintomatología. La exploración y la ecografía demuestran la existencia de un tumor testicular de gran tamaño con afectación retroperitoneal ganglionar. En la radiografía simple de tórax se evidencia la presencia de múltiples metástasis pulmonares que son confirmadas con la TAC, así como múltiples adenopatías inguinales y paratraqueales. En la analítica se halla una $\beta$-HCG de $17702 \mathrm{mUI} / \mathrm{ml}$ y una $\alpha$-FP de 28025 $\mathrm{ng} / \mathrm{ml}$. En octubre de 2002 se procede a orquiectomía radical derecha con un resultado anatomopatológico de tumor germinal mixto (compuesto de carcinoma embrionario, yolk sac tumor, teratoma maduro e inmaduro y mínimos focos de seminoma y coriocarcinoma). El estadio tumoral fue de T3N3M1a (estadio IIIC).
Tras varios ciclos de quimioterapia agresiva según el esquema BOMP/EPI, se produce respuesta parcial a la misma con reducción de las metástasis pulmonares, pero presenta una gran masa residual en la TAC realizada (Figs. 1 y 2), que obliga al planteamiento de cirugía exerética de la misma.

Se procede, tras adecuado estudio preoperatorio, a realizar linfadenectomía retroperitoneal y exéresis de masa residual mediante abordaje laparotómico medio xifopubiano. La masa englobaba, como se puede observar en la TAC, los grandes vasos desde la vena renal izquierda hasta la bifurcación de las arterias iliacas superficial y profunda izquierda y en menor medida en el lado derecho. Tras una compleja intervención se consigue exéresis completa de la masa quedando como resultado las imágenes que muestran las Figs. 3 y 4.
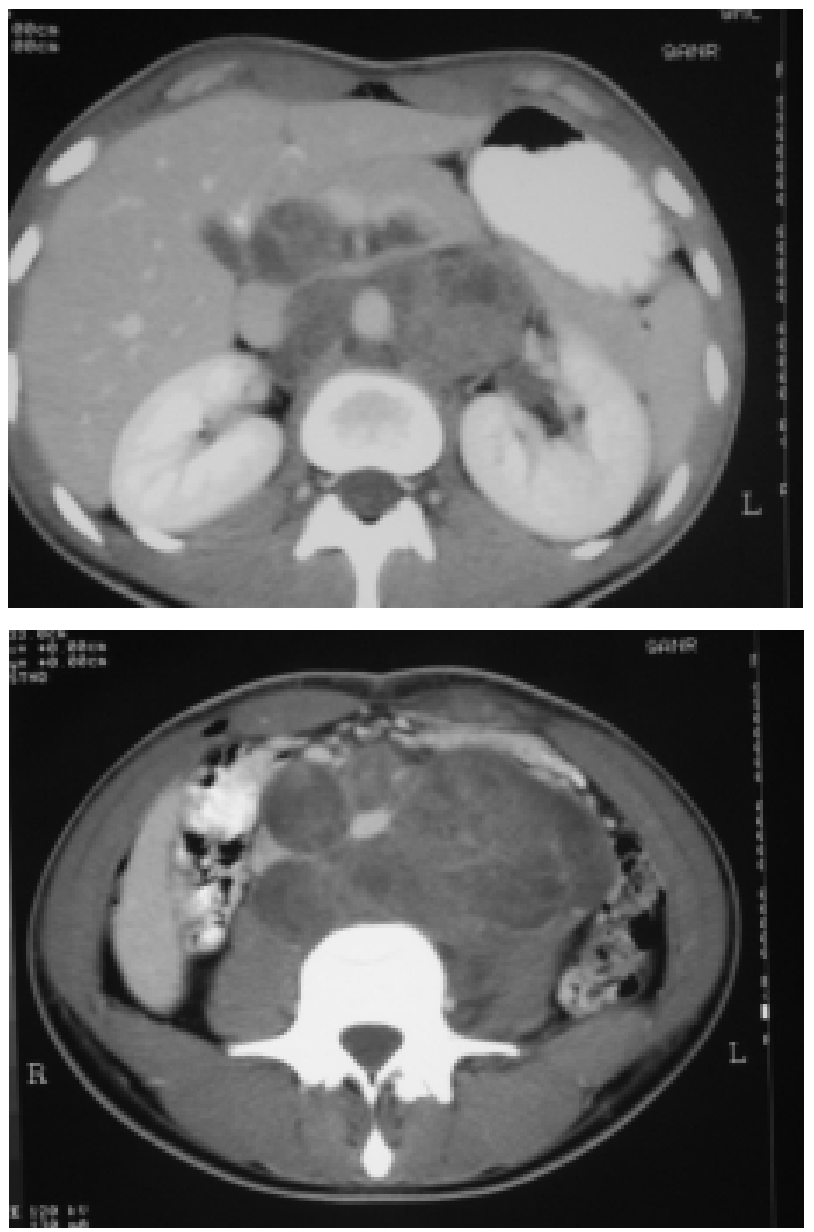

FIGURAS 1 y 2.- Imágenes de la TAC donde se aprecia la extensión de la masa residual englobando los grandes vasos. 

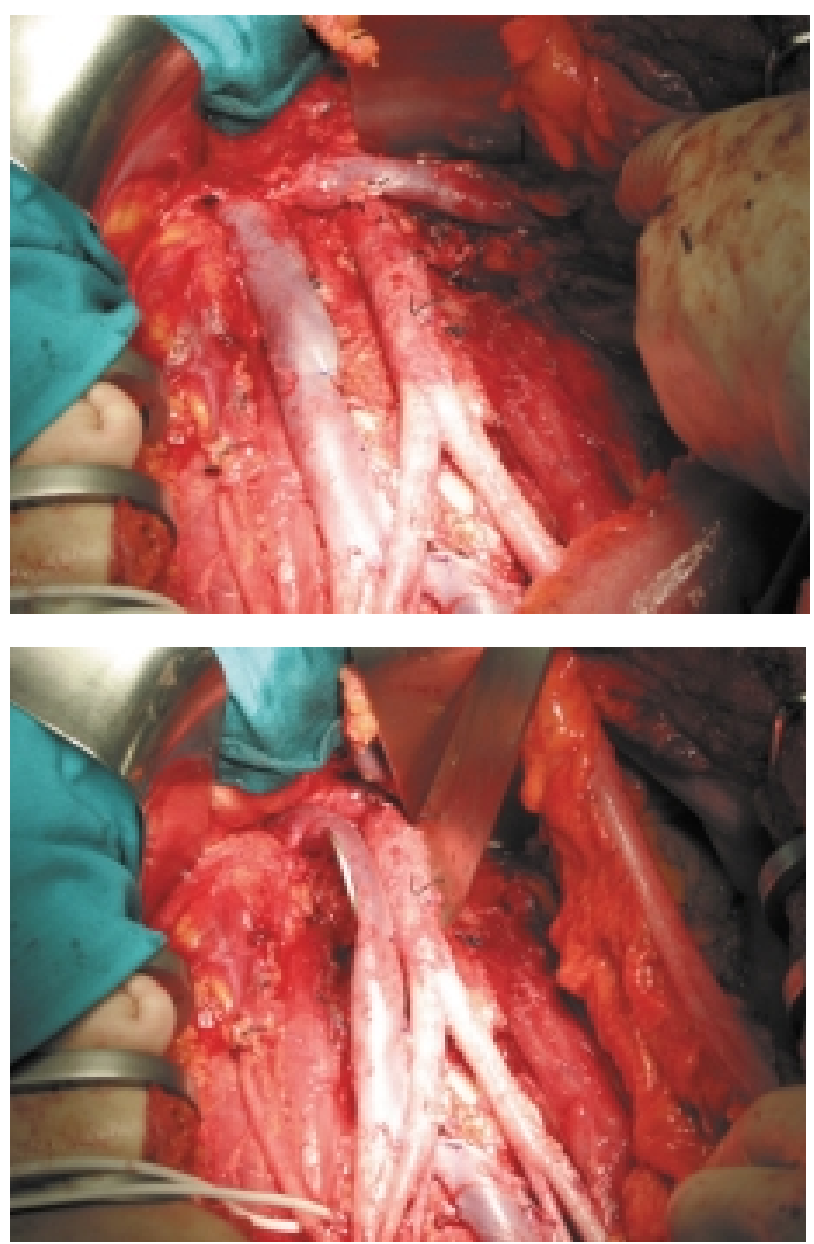

FIGURAS 3 y 4.- Imágenes postoperatorias mostrando el resultado tras la intervención, con los grandes vasos libres.

El estudio patológico de la masa revela tumoración teratomatosa madura. Actualmente el paciente es valorado por Oncología por si precisa nuevos ciclos de quimioterapia postcirugía, a fin de que remitan las metástasis pulmonares.

\section{DISCUSIÓN}

La edad de mayor incidencia de aparición de tumores germinales testiculares suele ser en el fin de la adolescencia, entre los 20 y 40 años, y en la infancia, de 0 a 10 años. Parece ser que la criptorquidia es uno de los factores etiológicos más frecuentemente asociados con la aparición de estas neoplasias ${ }^{2}$.

El retraso del diagnóstico se suele deber a la demora de consulta del paciente, y otras veces como consecuencia de un diagnóstico tardío. En los últimos años la detección de este tipo de tumo- res se produce de manera más temprana, sin embargo, cuando el diagnóstico es tardío se ha encontrado relación con el estadio patológico de la enfermedad ${ }^{1}$.

Con el desarrollo de la quimioterapia combinada a base de cisplatino se han conseguido mejorías notables en el tratamiento de los tumores germinales de testículo avanzados, llegando a obtenerse respuestas completas y duraderas en el 70-80\% de los casos. Con estos resultados se hizo necesaria la clasificación de los pacientes con tumores germinales avanzados en alto y bajo riesgo, con el objeto de no sobretratar con terapias excesivamente agresivas a algunos pacientes. No obstante, aquellos pacientes considerados como de alto riesgo (como el paciente presentado en este trabajo) siguen teniendo un pronóstico sombrío con una tasa de supervivencia libre de enfermedad a largo plazo menor del $50 \%{ }^{3}$.

La linfadenectomía retroperitoneal, desde la aparición de los modernos tratamientos quimioterápicos, se ha transformado en un procedimiento con indicaciones más limitadas. Sin embargo, hay casos en los que parece tener una clara indicación como son los tumores en estadios tempranos postorquiectomía y en los casos en los que aparece una masa residual tras tratamiento con quimioterapia, y sobre todo cuando ésta es de gran tamaño y presumiblemente de composición teratomatosa, que en su crecimiento puede conducir a la compresión de estructuras vecinas. Se presume que la presencia de tejido teratomatoso en la pieza de orquiectomía inicial predice que el $82 \%$ de la masa residual será teratomatosa ${ }^{4}$.

El tratamiento quirúrgico de la masa residual retroperitoneal resulta necesario en los pacientes con recurrencia tras la quimioterapia, y en los pacientes con cáncer activo permite, tras la nueva administración de quimioterapia, altos porcentajes de curación en los pacientes con teratoma ${ }^{5,6}$.

La linfadenectomía retroperitoneal es una técnica quirúrgica compleja con posibilidad de serias complicaciones, y más cuando se debe realizar exéresis de masa residual de tamaño considerable. Las complicaciones más frecuentes se derivan del daño a estructuras vasculares importantes durante el acto quirúrgico. También es frecuente la lesión del uréter. La aneyaculación y la eyaculación retrógrada es una de las conse- 
cuencias más frecuente encontrada en los pacientes sometidos a este procedimiento, pero se han desarrollado técnicas con preservación de nervios con alto porcentaje de éxitos ${ }^{7-9}$. En el caso que nos ocupa, esta posibilidad no fue viable por el tamaño de la masa y la fuerte adhesión de la misma a estructuras adyacentes.

En conclusión, los pacientes que presentan masa residual tras la administración de quimioterapia, precisan cirugía de la misma, ya que por sí sola, puede conseguir hasta un $70 \%$ de remisiones completas. Si bien, es importante que la cirugía haya sido lo más radical posible. El tratamiento de los tumores testiculares germinales avanzados requiere un abordaje multidisciplinario y un estrecho seguimiento de los pacientes, ya que se puede conseguir una curación a largo plazo $^{5,10}$. A pesar de tratarse de una cirugía compleja y con importantes complicaciones, los beneficios que puede aportar son grandes y se cuentan hoy en día con variantes técnicas que permiten conservar la eyaculación.

\section{REFERENCIAS}

1. FERNÁNDEZ GÓMEZ JM, GUATE ORTIZ JL, MARTÍN HUÉSCAR A, FRESNO FORCELLEDO F, ESCAF BARMADAH S, GARCIAA RODRIGGUEZ J, PÉREZ GARCÍA FJ, RODRÍGUEZ FABA O, JALÓN MONZÓN: Presentación clínica del cáncer germinal de testículo. Arch Esp Urol 2002; 55: 915-922.

2. RICHIE JP: "Neoplasms of the testis" En: Campbell's Urology. $7^{\text {a }}$ Ed. Walsh PC, Retick AB, Vaughan ED, Wein AJ. W.B. Saunders Company. Philadelphia. 1998; 2.411-2.452.
3. DODD PM, MOTZER RJ, BAJORIN DF: Tumores de células germinales de alto riesgo. Avances recientes. Urol Clin North Am 1998; 3: 525-534 (Ed. Española).

4. PREINER JL, JEWETT MA: Role for retroperitoneal lymphadenectomy for testis cancer. Curr Op Urol 1999; 9: 205-208.

5. SÁNCHEZ MARTÍN FM: Cirugía de la masa retroperitoneal. Arch Esp Urol 2000; 53: 535-546.

6. HENDRY WF, NORMAN AR, DEARNALEY DP, FISHER C, NICHOLLS J, HUDDART RA, HORWICH A. Metastasic nonseminomatous germ cell tumors of the testis. Cancer 2002; 15: 1.668-1.676.

7. GILJA I, PARAZADJET J, RADEJA M, CVITKOVIE P, KOVACIE M.: Eyaculación retrógrada y aneyaculación: posibilidades de tratamiento conservador. Eur. Urol. 1995; 2: 319-321 (Ed. Española).

8. SOLSONA E, IBORRA I, RICÓS JV, MONROS JL, DURMONT R, CASANOVA J, GUILLEM V. Preservación de la eyaculación anterógrada en la linfadenectomía retroperitoneal por masas residuales tras la quimioterapia inicial en el carcinoma testicular. Eur Urol 1995; 2: 293-296 (Ed. Española).

9. FERNÁNDEZ GÓMEZ JM, ESCAF BARMADAH S, GUATE ORTIZ JL, MARTIN HUÉSCAR A, FRESNO FORCELLEDO F, GARCÍA RODRÍGUEZ J, RODRÍGUEZ FABA O, JALÓN MONZÓN, RODRÍGUEZ MARTÍNEZ JJ.: Tratamiento urológico del cáncer germinal de testículo. Arch Esp Urol 2002; 55: 927 936.

10. DROZ JP, RIVOIRE M.: Advanced testis cancer. Curr Treat Op Oncol 2001; 2: 421-429.

Dr. J.M. Giménez Bachs

C/ Salamanca, 4 - 5o dcha.

02001 Albacete

(Trabajo recibido el 5 mayo de 2003) 